\title{
Assessment of balance, gait, lower limb strength and functionality in sarcopenic and non-sarcopenic elderlies
}

\author{
Alice Martins de Magalhães, Barbara Batista Gomes, Daniella Macedo Cerceau, Gabriela Vieira de Oliveira, \\ Kênia Kiefer Parreiras de Menezes
}

Faculdade de Desenvolvimento das Ciências e Humanidades, Fundação Comunitária de Ensino Superior de Itabira (FADECH/FUNCESI). Itabira (MG), Brazil.

\section{ABSTRACT}

Background: Sarcopenia is the involuntary loss of muscle mass predicted by aging and is associated with an increased likelihood of unfavorable results, such as falls, mortality and functional disabilities. Objective: Evaluate balance, gait speed, lower limb strength and functionality in sarcopenic and non-sarcopenic elderly. Methods: Cross-sectional study, carried out with 68 subjects aged 60 years or over, residents of the community and possessing an independent gait. The assessment instruments were bioimpedance, balance test, four-meter gait speed test, chair support test and SPPB. Results: The prevalence of sarcopenia in the population of the present study was $43.3 \%$. In the group of non-sarcopenic subjects, a correlation was found between all the variables evaluated. In the group of sarcopenic subjects, a correlation was found between lower limbs strength and gait speed. Conclusion: The skeletal muscle mass of a sarcopenic elderly is related to their lower limb strength and gait speed, but it does not present a significant correlation with balance and functional performance. Further studies are needed to clarify the behavior of balance, gait speed, lower limb strength and functional performance variables when compared to the decrease in muscle mass inherent in aging.

Keywords: Balance; Strength; Functionality; Sarcopenia; Speed.

\section{BACKGROUND}

Population aging is a worldwide phenomenon ${ }^{1}$. The number of elderly people in Brazil, from 2012 to 2017 , increased from 25.4 to 30.2 million, which represents an $18 \%$ growth in the age group ${ }^{(1)}$. The aging process is accompanied by the appearance of chronic diseases and marked by changes in body composition, including an increase in adipose tissue and a decrease in skeletal muscle mass ${ }^{(2)}$. Sarcopenia is the involuntary loss of skeletal muscle mass predicted by the aging process ${ }^{(3)}$.

Authors state that after 50 years of age, the muscle mass rate decreases approximately $1.0 \%$ per year ${ }^{(4)}$. Its diagnosis can be made through magnetic resonance imaging (MRI), ultrasound, computed tomography (CT), bioimpedance (BIA), anthropometry and functional tests ${ }^{(5)}$. Studies indicate different prevalence rates, ranging from 5 to $22 \%{ }^{(6)}$. Sarcopenia is progressive, widespread and is associated with an increased likelihood of unfavorable outcomes, such as falls, mortality and functional disabilities ${ }^{(7)}$. Functional disability is defined as the limitation of an subject's ability to perform usual tasks of daily living ${ }^{(8)}$. From the fourth decade of life onwards, it can already be seen considerable losses in biological systems that reflect functional changes ${ }^{(9)}$. The reduction in functionality causes negative effects on well-being, generating the need for health care and long-term care ${ }^{10}$. On the other hand, maintaining or gaining functionality in the elderly, promotes aging with a higher quality of life, capable of restoring impaired body homeostasis ${ }^{(10)}$.

Studies show that variables such as balance, gait speed and muscle strength directly interfere in the functional capacity of the elderly, becoming important aspects in assessing the physical and functional performance of this population ${ }^{(11)}$.

The early diagnosis of sarcopenia is clinical relevant since the association of reduced muscle mass and strength results in a greater risk of falls, hospitalizations, dependence, institutionalizations, worsening quality of life and mortality ${ }^{(2)}$. Added to these aspects, the serious social and economic repercussions $^{(3)}$. After the identification of sarcopenia, it can be reversed through proper exercise and nutritional intervention, directly impacting the physical and functional performance of subjects ${ }^{(5)}$. Sarcopenia is the subject of several studies, has multiple diagnostic criteria and it is still neglected and under-diagnosed in clinical practice $^{(5)}$. Therefore, the aim of this study was to assess static balance, gait speed, lower limb strength and functionality in sarcopenic and nonsarcopenic elderly in the community. 


\section{METHODS}

\section{Study design}

This is an observational cross-sectional study approved by the Research Ethics Committee of FUNCESI, in 2019, with number 13923919.6.0000.5110.

\section{Sample Calculation}

The sample calculation was based on the correlation coefficients between the variables, found in a pilot study with 10 subjects. Considering alpha of 0.5 , a power of 0.8 and assuming the lowest coefficient found in the pilot ( $p=0.30)$, balance and gait speed, the necessary sample would be 68 subjects $^{(12)}$.

\section{Sample}

This study was conducted with elderly residents of the city of Itabira in Minas Gerais, who sought the physiotherapy service of the city's Unified Health System (SUS), through the Rehabilitation Center. Men and women aged 60 years and over, residents of the community and those with independent gait were included. Exclusion criteria were: elderly people with disabling musculoskeletal conditions; possessing a pacemaker or other electronic device attached to the body; who had metallic implants in both hemibodies; presence of any type of bleeding; amputees; and with motor, visual or hearing sequelae that would make it impossible to perform the tests. Participants were previously advised, by telephone, not to consume alcohol and caffeine 24 hours before the test, in addition to not performing intense physical activity.

\section{Data collection}

The data collection for the study was carried out at the physiotherapy outpatient clinic of FUNCESI's school in the months of August and September 2019. Two researchers (BBG and GVO), blinded with respect to the results of both, collected the information from the study. After signing the informed consent form, participants were submitted to the collection of personal and anthropometric information, health history and vital data (APPENDIX A). Then, examiner A collected the values of fat percentage (\%), fat mass in kilograms $(\mathrm{kg})$, lean mass in $\mathrm{kg}$ and amount of body fluid in liters (L) by the electrical bioimpedance test (BIA) with the device model Biodynamics 310E.

To perform the BIA exam, the participants were instructed to position themselves in the supine position, with the upper and lower limbs slightly abducted, on a non-conductive surface ${ }^{(13)}$. The silicone electrodes were positioned unilaterally on the back of the feet, in the metatarsal region, and on the back of the hands, in the metacarpal region, according to the manufacturer's instructions. The body composition data were recorded on the patient's chart. Subsequently, in another room, researcher B collected data on static balance, gait speed, lower limb strength by the chair support test and the Short Physical Performance Battery (SPPB) to assess functionality ${ }^{(11)}$.

For the balance test, participants were instructed to hold for 10 seconds in each position, side-by-side, semi-tandem stand, tandem stand, respectively. In the gait speed test, the elderlies were instructed to walk at a normal pace, over a distance of four meters, measured in two steps, back and forth. In the chair support test, participants were instructed to sit and stand up five times in a row without the help of their upper limbs. To obtain the SPPB score, the values of the balance test, gait speed and chair support test were used. For the timing of the tests, the digital timer was used Cronobiomodelo SW20 (13).

\section{Statistical Analysis}

Descriptive statics and normality tests (Kolmogoroy-Smirnov) were performed for all variables. Spearman's correlation coefficient was used to assess the correlations between balance, functional capacity by the gait speed test and strength of sitting and standing by the chair support test. The strength of the correlations was classified as low $(r<0.30)$, moderate $(0.30 \leq r \geq 0.50)$ and high ( $r>0.50) 12$. All analyzes were performed with the statistical software SPSS 23.0 with a significance of $5 \%$.

\section{RESULTS}

In the months of August and September, 72 elderly people were included in the data collection, five were excluded according to the exclusion criteria, leaving 67 elderly people aged between 60 and 88 years and an average of 71.5 years. The majority of the elderly were female $(65.83 \%)$ and of the self-titled brown race $(40.30 \%)$; just over half $(55.22 \%)$ were married and only $37.31 \%$ practiced physical activity. The characteristics of the participants are shown in Table 1.

According to the BIA of the 67 elderlies, 29 (43.3\%) were considered sarcopenic. The mean fat mass for non-sarcopenic subjects was $31.1 \mathrm{~kg}$ and for the sarcopenic group it was $23 \mathrm{~kg}$. The mean skeletal muscle mass in the non-sarcopenic group was $47.86 \mathrm{~kg}$ and in the sarcopenic group it was $35.67 \mathrm{~kg}$ (Table 2). 
Table 1. Socioeconomic, demographic and physical activity variables of the elderlies.

\begin{tabular}{lcc}
\hline Variables & $\mathrm{n}$ & $(\%)$ \\
\hline Gender & 51 & 76.11 \\
$\quad$ Female & 16 & 23.89 \\
$\quad$ Male & & \\
Age & 41 & 61.20 \\
$\quad 60-69$ years & 22 & 32.83 \\
$70-79$ years & 04 & 5.97 \\
80 years or more & & \\
Civil status & 10 & 14.92 \\
$\quad$ Not married & 37 & 55.22 \\
Married or cohabited & 02 & 2.99 \\
$\quad$ Divorced or separated & 18 & 26.87 \\
$\quad$ Widow/Widower & & 22.39 \\
Ethnicity & 15 & 40.30 \\
$\quad$ Caucasian & 27 & 37.31 \\
Africans & 25 & 37.31 \\
$\quad$ Brown & 25 & \\
Practices physical activity & & \\
\hline
\end{tabular}

Table 2. Bioinpedance values for sarcopenic and non-sarcopenic participantes.

\begin{tabular}{lcc}
\hline Data & Non-sarcopenic mean & Sarcopenic mean \\
\hline Fat mass & 31.10 & 23.00 \\
Mass (reference) & 16.95 & 11.66 \\
Skeletal muscle mass & 47.86 & 35.67 \\
Skeletal muscle mass(reference) & 47.86 & 36.11 \\
\hline
\end{tabular}

It was observed when assessing the nutritional status of the elderly, the prevalence of overweight (25 elderlies, $37.31 \%$ ) and obesity (23 elderlies, $34.32 \%$ ) - totaling 48 elderly people over ideal weight (more than $70 \%$ ). Participants reported the existence of several health problems, with systemic arterial hypertension (SAH) being the most frequent (49-73.13\%). As a consequence of several morbidities, polypharmacy appeared the elderly had an average use of six medications. Table 3 shows the health data of the participants.

Table 3. Nutritional and comorbidities of the elderlies.

\begin{tabular}{ll}
\hline Health condition & $\mathrm{n}(\%)$ \\
\hline Nutritional status by BMI & \\
$\quad$ Eutrophy & $19(28.36)$ \\
Overweight & $25(37.31)$ \\
Obesity & $23(34.32)$ \\
SAH & $49(73.13)$ \\
MD & $23(34.32)$ \\
Dyslipidemia & $23(34.32)$ \\
Smoking & $03(4.48)$ \\
Alcoholism & $01(1.50)$ \\
\hline Note: BMI: body mass index; SAH: systemic arterial Hypertension; MD: medical disorders
\end{tabular}

"Note: BMI: body mass index; SAH: systemic arterial Hypertension; MD: medical disorders 
When relating the variables evaluated in the present study, in the non-sarcopenic preference group, a correlation was found in all tests, except in the SPPB that evaluated the functionality. In the sarcopenic search group, a high correlation ( $r>$ 0.574 and $p<0.001$ ) was found between the chair support test that predicts the strength of lower limbs. No correlation was found between skeletal muscle mass, static balance, and functionality assessed by SPPB in the group of desired sarcopenics.

\section{DISCUSSION}

The prevalence of sarcopenia in the population of the present study was $43.3 \%$ (34.32\% for women and $8.96 \%$ for men). Values with great discrepancy were found in the literature. The study of Patel et al. $(2013)^{(14)}$, carried out with 1,787 elderly people in the United Kingdom who classified $4.6 \%$ in men and $7.9 \%$ in women as sarcopenic. Another study, performed by Janssen et al.(2002) ${ }^{(13)}$ report a total prevalence of sarcopenia in elderlies aged 60 years or over was $7.0 \%$ among men and $10.0 \%$ among women. A third study, this time a Brazilian one, carried out in the city of São Paulo by Alexandre et al. $(2013)^{(6)}$, assessed $14.4 \%$ men and $16.1 \%$ women as sarcopenic. The high percentage of elderly people with sarcopenia found in the present study can be justified by the sample's characteristics.

All the studies mentioned above evaluated healthy elderly people, the present study recruited elderly people who needed rehabilitation and waited in line for the city's physical therapy service for several months. Some of them had chronic pain that aggravated health conditions and decreased performance of activities and participation, according to the International Classification of Functionality (CF). It is known, according to what is already described in the literature, that men and women who perform less physical activities also have less muscle mass, which justifies the high prevalence of sarcopenia in the evaluated group ${ }^{(15)}$.

Within the sample of the present study, half of the subjects over 80 years old were considered sarcopenic, exactly $50 \%$ of the subjects in this age group, as in the study by Baumgartner et al. $(1998)^{(16)}$, who reported a 13 to $24 \%$ prevalence of sarcopenia in subjects of both genders up to 70 years old and in subjects over 80 years old, the percentage increased to more than $50 \%$, showing a direct relationship between sarcopenia and increasing age.
Regarding the nutritional status of the elderly, the results showed that $37.31 \%$ were overweight and $34.32 \%$ were obese, totaling $71.6 \%$ of subjects with a high percentage of body fat. It is known that the peaks in adipose tissue occur between 60 and 70 years of age, and that this nutritional transition is associated with changes in eating behavior and in reducing the degree of physical activity of subjects in this age group ${ }^{(17)}$. Among the obese elderly, $13.04 \%$ had sarcopenic obesity. In the study by Santos et al. $(2017)^{(18)}$ the prevalence of sarcopenic obesity was $4.9 \%$ in a sample of both sexes, but performed with subjects aged 50 years or over, that is, ten years younger than the sample in this study, which justifies the lower percentage found.

Among the group of non-sarcopenic subjects, a correlation was found between all variables evaluated, stating what was already described in the literature. Aveiro et al. (2013) ${ }^{(19)}$ claim that muscle strength is paramount for maintaining balance. Hauser et al. (2013) ${ }^{(20)}$ in a study carried out with the elderly, they evaluated lower limb strength, also statistically proved the correlation between balance and muscle strength. In relation to balance and gait speed, it is known that decreased balance causes postural changes, especially in the sagittal plane, as a strategy to keep the center of mass within the limits of the body's support base, such changes cause a decrease in the gait speed ${ }^{(21)}$. In this context, the study performed by Santos et al. (2016) ${ }^{(22)}$ proved that elderly people evaluated with less balance by the Berg scale, presented lower gait speed. Lastly, Buchne et al. (1996) ${ }^{(23)}$, in a study of 409 elderly people, they reported a significant correlation between lower limb strength and walking speed.

When relating the variables in the group of sarcopenic subjects, a high correlation ( $p>0.001)$ was found between muscle strength by the chair support test and gait speed. The statistical analysis of the present study proved that the lower the muscle strength, the greater the time spent to cover a distance of 4 meters. Sowers et al. $(2005)^{(24)}$ in their observational study, they correlated for the first time the decrease in lean mass common with aging with lower limb strength and gait speed. Since then, several other authors have confirmed the claim, among them, the work of Garcia et al. (2008) ${ }^{(25)}$ performed with 81 elderly Brazilians and who used the isokinetic dynamometer to assess muscle strength of the lower limbs.

Regarding the static balance of the sarcopenic group, no significant correlation was found with the other variables evaluated. Gadelha $(2018)^{(9)}$, in the study of 196 women, concluded that balance is negatively affected by sarcopenia. With the decrease in muscle mass it is expected that there 
will be a decrease in balance, since the anticipatory and compensatory balance strategies need neuromuscular activation especially of the ankle, knee and hip ${ }^{(26)}$.

However, in the present study, both nonsarcopenic and sarcopenic subjects presented satisfactory results in the assessment of static balance. It is believed that the choice of the sample composed of elderly people from the community, ble to seek health care and who were willing to go to the clinic where the data for this work was collected, directly interfered with the results regarding balance. Thus, the active lifestyle positively interfered with the postural stability conditions of the elderly participants. Thus, it is suggested to carry out further studies, with different populations of elderly people, that compare muscle mass and static balance.

When relating sarcopenic and non-sarcopenic subjects to SPPB, no significant correlation was found between the mass of these subjects and the test score. However, Neves et al. $(2018)^{(27)}$ in a study that evaluated skeletal muscle mass, nutritional aspects, functionality and physical performance in the elderly, found a correlation between all variables evaluated. It is believed that the characteristic of the elderly population chosen for the study also interfered with this result. Most of the subjects evaluated had their performance classified as moderate, which can be explained by the fact that the SPPB evaluates important aspects of locomotion and mobility, variables preserved in a sample of elderly in the community, characterizing a selection bias.

The structural and functional changes resulting from sarcopenia, such as strength and gait speed, confirmed in the present study, lead to changes in activities and social participation and are perceived by the elderly ${ }^{(28)}$. Sitting and getting up from seats, carrying objects, walking at a safe speed, going up and down stairs are vital activities for the health and independence of the elderly ${ }^{37-39}$.

In this context, one of the limitations of this study was the failure to investigate how much these changes interfere with important functional activities specific to each subject. One of the ways to carry out this evaluation would be the use of questionnaires of activities of daily living (ADL) and instrumental activities of daily living (IADL), such as the Katz, Lawton or Pfeffer questionnaires which are accessible, easy to apply and which allow screening decrease in functionality in different populations ${ }^{(29}$, 30).

\section{CONCLUSION}

The present study pointed out that the skeletal muscle mass of a sarcopenic elderly person in the community correlates with his lower limb strength and gait speed, but does not have a significant correlation with balance and functional performance. New studies, with a more comprehensive population, are needed to clarify the behavior of the variables of lower limb strength, gait speed, static balance and functional performance when compared to the decrease in muscle mass inherent to aging.

Authors' contributions: AMM and DMC: responsible for the project design, organization of articles for reading, writing the introduction, methodology and discussion. BBG and GVO: responsible for writing all sessions, phone calls to patients and data collection. KKPM: responsible for reviewing the entire text and statistical analysis.

Financial support: The authors declare that there are nonfinancial competing interests

Conflict of interest: The authors declare that there was no conflict of interests.

\section{REFERENCES}

1. Kalache A, Veras RP, Ramos LR. O envelhecimento da população mundial: um desafio novo. Revista Saúde Pública. 1987;21(3):200-10.

2. Frontera WR, Hughes VA, lutz KJ, Evans WJ. A cross sectional study of muscle strength and mass in 45- to 78-yr-old men and women. Journal of Applied Physiology.1991;71(2):64450.

3. Pisciottano MV, Pinto SS, Szejnfeld VL, Castro $\mathrm{CHM}$. The relationship between lean mass, muscle strength and physical ability in independent healthy elderly women from the community. The Journal Nutriton Health \& Aging. 2014;18(5):554-8.

4. Rosenberg, Irwin H. Summary comments. The American Journal of Clinical Nutrition v. 50 , n.5 p.1231-1233. 1989

5. Cruz-Jentoft AJ, Bahat G, Bauer J, Boirie $Y$, Bruyère $O$, Cederholm $T$, et al. Writing Group for the European Working Group on Sarcopenia in Older People 2 (EWGSOP2), and the Extended Group for EWGSOP2. Sarcopenia: revised European consensus on definition and diagnosis. Age Ageing. 2019;48(1):16-31 .

6. Alexandre TS, Duarte YA, Santos JL, Wong R, Lebrão ML. Prevalence and associated factors of sarcopenia among elderly in Brazil: findings from the SABE study. J Nutr Health Aging. 2014;18(3):284-90.

7. Goodpaster BH, Park SW, Harris TB, Kritchevsky SB, Nevitt M, Schwartz AV, et al. The loss of skeletal muscle strength, mass, and 
quality in older adults: the health, aging and body composition study. J Gerontol A Biol Sci Med Sci. 2006;61(10):1059-64.

8. Bessa LB; Barros NV. Impacto da sarcopenia na funcionalidade de idosos. 2009. $22 f$. Trabalho de Conclusão de Curso. (Fisioterapia) Universidade Federal de Minas Gerais. Belo Horizonte. 2009 Disponível em <http://www.eeffto.ufmg.br/biblioteca/1734.pdf> . Acesso em 23 de abril de 2019.

9. Gadelha AB. Associação entre estágios da sarcopenia, Risco de quedas, Equilíbrio Estático e Incidência de Quedas em Mulheres Idosas. 2018. 153f. Tese (Doutorado em Educação Física). Universidade de Brasília, Brasília, 2018.

10. Frank S, Santos, SMA, Assman, AA, Alves KL, Ferreira N. Avaliação da capacidade funcional: repensando a assistência ao idoso na Saúde Comunitária. Estudo Interdisciplinar do Envelhecimento. 2007;11:123-34.

11. Guralnik J, Simonsick E, Ferrucci L, Glynn R, Berkman L, Blazer D, et al. A Short Physical Performance Battery Assessing Lower Extremity Function: Association with self-reported disability and prediction of mortality and nursing home admission. Journal of Gerontology: Medical Sciences. 1994;49(2):85-94.

12. Janssen I, Heymsfield S, Ross R. Low Relative Skeletal Muscle Mass (Sarcopenia) in Older Persons Is Associated with Functional Impairment and Physical Disability. Journal American Geriatrics Society. 2002;50(5):889896.

13. Cohen J. Statistical Power Analysis for the Behavioral Sciences. $2^{\circ}$ Edition. Nova York. Lawrence Erlbaum Associates Publishers, 1988.

14. Patel HP, Syddall HE, Jameson K, Robinson S, Denison $\mathrm{H}$, Roberts $\mathrm{HC}$, et al. Prevalence of sarcopenia in community-dwelling older people in the UK using the European Working Group on Sarcopenia in Older People (EWGSOP) definition: findings from the Hertfordshire Cohort Study (HCS). Age and Ageing. 2013;42(3):378384.

15. Picoli TS, Figueiredo LL, Patrizzi LJ. Sarcopenia e envelhecimento. Fisioterapia em movimento. $2011 ; 24(3): 455-462$.

16. Baumgartner RN, Koehler KM, Gallagher D, Romero L, Heymsfield SB, Ross RR, et al. Epidemiology of Sarcopenia among the Elderly in New Mexico. American Journal of Epidemiology.1998;147(8):755-763.

17. Hajek A, Lehnert T, Ernst A, Lange C, Wiese B, Prokein $\mathrm{J}$, et al. Prevalence and determinants of overweight and obesity in old age in Germany. BMC Geriatric. 2015;15(1):1-13.
18. Santos IR, Carvalho RC, Lima, KBSP, Silva SC, Ferreira AS, Vasconcelos NN et al. Análise dos parâmetros da marcha e do equilíbrio dos idosos após exercícios aeróbicos e terapêuticos. Arquivo de Ciência e Saúde. 2016;20(1):19-23.

19. Aveiro MC, Driusso P, Santos JG, Kiyoto VD, Oishi J. Effects of a group-based exercise program on muscle strengt and postural controlamong community- dwelling elderly women: a randomized-controlled trial. Revista Brasileira de Geriatria e Gerontologia. 2013;16(3):527-540.

20. Hauser E, Martins VF, Teixeira AR, Zabaleta AD, Gonçalves AK. Relação entre força muscular e equilíbrio de idosos no programa de equilíbrio. ConScientia e Saúde. 2013;12(4):580-587.

21. Carvalho EMS, Mota SPF, Silva GPF, Filho JMC. A postura do idoso e suas implicações clinicas. Geriatria \& Gerontologia. 2011;5(3):170-174.

22. Santos VR, Araújo MYC, Cardoso MR, Batista VC, Christofaro DGD, Gobbo LA. Análise da associação da prática insuficiente de atividade física com sarcopenia e obesidade sarcopênica em indivíduos com idade igual ou superior a 50 anos. Rev. Nutr. 2017;30(2)

23. Buchner DM, Larson EB, Wagner EH, Koepsell TD, Lateur BJ. Evidence for a non-linear relationship between leg strenght and gait speed. Age Ageing.1996;25(5):386-391.

24. Sowers MFR, Crutchfield M, Richards K, Wilkin MK, Furniss A, Jannausch M, et al. Sarcopenia Is Related to Physical Functioning and Leg Strength in Middle-Aged Women. Journal of Gerontology: Medical Sciences. 2005;60(4):486-490.

25. Garcia PA. Sarcopenia, Mobilidade Funcional e Nível de Atividade Física em Idosos Ativos da Comunidade. 2008. 91 p. Dissertação (Mestrado em Ciência da Reabilitação) - Escola de Educação Física, Fisioterapia e Terapia Ocupacional. Universidade Federal de Minas Gerais, Belo Horizonte.

26. Scariot V, Claudino R, Santos LC, Rios JL, Santos MJ. Ajustes posturais antecipatórios e compensatórios ao pegar uma bola em condição de estabilidade e instabilidade postural. Fisioterapia e Pesquisa. 2012;19(3):228-235.

27. Neves T, Fett CA, Ferriolli E, Souza MGC, Filho ADR, Lopes MBM, et al. Correlation between muscle mass, nutritional status and physical performance of elderly people. Osteoporosis and Sarcopenia. 2018;4(4):145-149. 
28. Bandura $A$. The social foundations of thought and action: A social cognitive approach. Englewood Cliffs: Prentice Hall; 1986. 617p.

29. Katz S, Ford AB, Moskowitz RW, Jackson BA, Jaffe MW. The Index of ADL: A standardized measure of biological and psychosocial function. 1963;185(12):914-919.
30. Pfeffer RI, Kurosaki TT, Harrah CH, Chance JM, Filos S. Measurement of functional activities in older adults in the community. Journal of Gerontology, Washington. 1982;37(3):323-329. 